\title{
Predictors of radiographic joint damage in patients with early rheumatoid arthritis
} L M A Jansen, I E van der Horst-Bruinsma, D van Schaardenburg, P D Bezemer,
B A C Dijkmans

\begin{abstract}
Objective-To determine factors at diagnosis, associated with radiographic damage at diagnosis and after one year, in patients with early rheumatoid arthritis (RA).
\end{abstract}

Methods-New patients with early RA were followed up for one year. Possible prognostic factors were duration of complaints, morning stiffness, disease activity score (DAS28), functional status (Health Assessment Questionnaire (HAQ) score), rheumatoid factor (IgM RF), and $\mathrm{C}$ reactive protein (CRP). Outcome was defined as radiographic damage of the hands and feet (Sharp/van der Heijde score). For the statistical analysis, one way analysis of variance and a forward stepwise logistic regression model was used. Results-130 patients with RA (68\% female; median age 64 years, range 21-86) were included. Despite the fact that the median duration of complaints was short (15 weeks, range $2-106$ ) the radiographic damage at diagnosis was significantly correlated with the duration of complaints $(p<0.05)$. Patients with a duration of complaints of $>34$ weeks had significantly more radiographic joint damage at diagnosis than patients with a shorter duration of complaints. Radiographic progression at one year was correlated with high radiographic joint damage, high CRP level, and a positive IgM RF at entry. Conclusions-In early RA, the number of radiographic lesions was correlated with $a$ longer duration of complaints at the first visit. Progression of these lesions was predicted by a high baseline joint damage, high CRP level, and a positive IgM RF. Further reduction of the delay in referral and early treatment may further decrease joint damage in patients with recent onset polyarthritis.

(Ann Rheum Dis 2001;60:924-927)

Epidemiology and Biostatistics, Vrije

Universiteit,

Amsterdam, The

Netherlands

P D Bezemer

Correspondence to: Professor B A C Dijkmans, Department of Rheumatology, Free University Hospital, Room B417, PO Box 7057, 1007

MB Amsterdam, The

Netherlands

jansen_annemarie@

hotmail.com

Accepted 27 February 2001 early stage, even within two years after disease onset in the vast majority (70-93\%) of patients. ${ }^{1-4}$ The rate of appearance of erosions is high in the early years of RA. ${ }^{56}$ In the long term, joint damage may lead to functional disability. ${ }^{4}$ In a study by Corbett et al the onset of erosions in hands and feet during the first two years of disease was the strongest predictive feature of a poor functional outcome after 15 years. $^{7}$
If, at an early stage, those patients who will deteriorate rapidly could be recognised, a more appropriate treatment could be given. Several recent studies suggest that fast and aggressive treatment of RA by combining disease modifying antirheumatic drugs (DMARDs) will suppress the inflammation process and result in less joint destruction..$^{8-12}$ In the long term, this may preserve the functional outcome as well. ${ }^{4}$ Many studies have examined the course and outcome of disease in patients with established RA and investigated the role of variables measured at the patient's initial visit as prognostic factors. Factors at initial presentation which are reported as predictors for joint damage in patients with RA are female $\operatorname{sex}^{13}$; serum IgM rheumatoid factor (RF) positivity $^{3413-22}$; the $\mathrm{C}$ reactive protein (CRP) level $1^{15} 16212324$; radiographic damage ${ }^{14} 17182125$; number of swollen joints ${ }^{16}{ }^{18}$; disease activity; ${ }^{4}{ }^{20}$ and the presence of the genetic marker HLA-DR4. ${ }^{17}{ }^{20}$ The definition of early arthritis varies in these studies because the interval between symptom onset and presentation to the rheumatologist ranges from three months to six years. Difference in study design is probably the most important reason for the conflicting results found in published reports.

In this study a cohort of patients with early RA with a median duration of complaints of 15 weeks was followed up for one year. The purpose of the study was: (a) to determine which parameters correlate with radiographic damage at the time of the diagnosis RA, and (b) to identify variables at the first visit that can predict radiographic progression after one year.

\section{Methods}

PATIENTS

As part of a prospective cohort study ${ }^{26}$ all patients with RA, fulfilling the American College of Rheumatology criteria for $\mathrm{RA}^{27}$ within one year after presentation, were followed up at a large rheumatology outpatient clinic. They were referred between September 1995 and September 1996. The duration of symptoms was at most two years. All patients gave informed consent. The medical ethical committee approved the study protocol. Patients who had been previously treated with a DMARD were excluded.

\section{DISEASE PARAMETERS}

After receiving the diagnosis RA by a rheumatologist, the patients were seen by a research nurse who performed a structured interview and physical examination. Follow up assessments were performed at 3, 6, 9, and 12 months. 
Table 1 Baseline and one year characteristics of 130 patients with early rheumatoid arthritis

\begin{tabular}{lll}
\hline Variable & Baseline & 1 Year \\
\hline Age (years), median (range) & $64(21-86)$ & - \\
Female (No (\%)) & $88(68)$ & - \\
Disease duration (months), median (range) & $3(0-24)$ & - \\
IgM RF ${ }^{\star}$ positive (No (\%)) & $66(51)$ & $62(54)$ \\
Erosive (No (\%)) & $100(77)$ & $98(86)$ \\
Radiographic score (S/H score), median (range) & $4(0-61)$ & $9(0-112)$ \\
DAS ${ }^{\star}$, mean (SD) & $5.4(1.2)$ & $3.8(1.4)$ \\
ESR $^{\star}$ (mm/1st h), mean (SD) & $40(24)$ & $20(17)$ \\
Morning stiffness (min), mean (SD) $_{\text {No of tender joints (38 joint count), median (range) }}$ & $34(42)$ & $15(22)$ \\
No of swollen joints (38 joint count), median (range) & $100(150)$ & $38(102)$ \\
HAQ & $12(1-33)$ & $5(0-32)$ \\
& $1.0(0.8)$ & $7(0-26)$ \\
\hline
\end{tabular}

${ }^{\star} \mathrm{RF}=$ rheumatoid factor; DAS = disease activity score; ESR = erythrocyte sedimentation rate; $\mathrm{CRP}=\mathrm{C}$ reactive protein; $\mathrm{HAQ}=$ Health Assessment Questionnaire.

At baseline, demographic characteristics, the time of onset of complaints (persistent pain and swelling), serum rheumatoid factor (IgM $\mathrm{RF}$ ), and radiographs of hands and feet were recorded. Every three months the following variables were assessed: the 28 joint disease activity score (DAS28: a composite score based on erythrocyte sedimentation rate (ESR), number of painful and number of swollen joints (both by 28 joint count), and patient global assessment by visual analogue scale (VAS) $),{ }^{28}$ the number of painful and number of swollen metatarsophalangeal joints, pain (VAS), CRP, and functional status by the validated Dutch version of the Health Assessment Questionnaire (HAQ). ${ }^{29}$

Outcome was assessed by counting the number of erosions and grading the joint space narrowing according to the van der Heijde modification of Sharp's method. ${ }^{25}{ }^{30}$ The main difference from the original Sharp method was the inclusion of the feet in the scoring system. The maximum number of erosions in the hands is 160 and in the feet 120 , and the maximum scores for joint space narrowing for hands and feet are respectively 120 and 48 . The maximum total score is 448. All radiographs were scored by a trained researcher, who was unaware of the clinical data of the patients. The $x$ ray pictures were read in pairs with unknown time sequence. Radiographic progression, expressed as delta $(\delta)$ damage, was computed by subtracting the initial Sharp van der Heijde score from the one year Sharp/van der Heijde score.

\section{STATISTICAL ANALYSIS}

Patients were split into five centile groups according to the duration of complaints: $0-7$ weeks, 8-13 weeks, 14-19 weeks, 20-33 weeks, and 34-104 weeks. Because of a skewed distribution the joint damage score was log transformed. One way analysis of variance was used to test whether the groups differed in baseline joint damage.

At one year the patients were divided into two groups, "slowly progressive" or "rapidly progressive", using the median of the $\delta$ damage. Subsequently, clinically relevant baseline characteristics were entered into a forward stepwise logistic regression analysis using the $\delta$ damage between the baseline and one year as dependent variable. The initial Sharp/van der

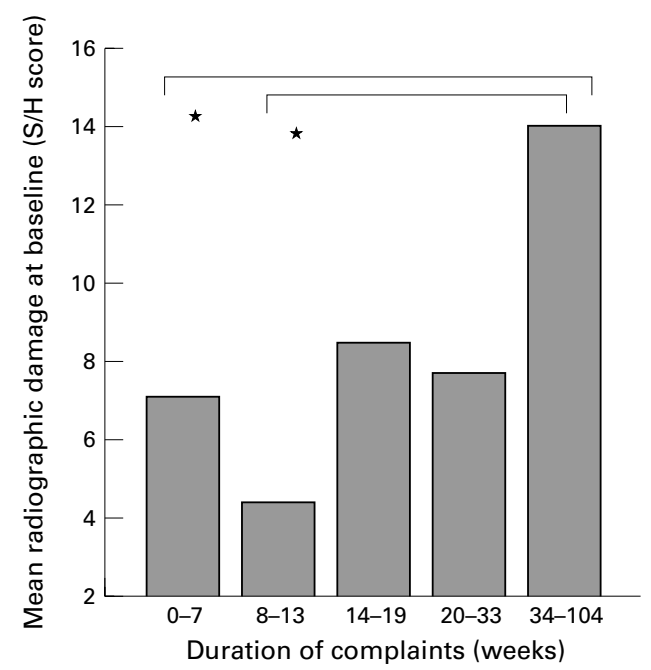

Figure 1 Radiographic damage at baseline in five centile groups by duration of complaints. ${ }^{\star} p<0.05$ (one way analysis of variance) $. S / H$ score $=$ Sharp/van der Heijde score.

Heijde score, age, sex, duration of complaints, DAS28 score, number of tender and swollen joints (38 joint count), HAQ score, IgM RF positivity, ESR high ( $\geqslant 28 \mathrm{~mm} / 1 \mathrm{st} \mathrm{h}) /$ low, and $\mathrm{CRP}$ high $(\geqslant 20 \mathrm{mg} / \mathrm{l}) /$ low were considered as independent variables. For the statistical methods used we refer to Altman. ${ }^{31}$ All analyses were carried out with SPSS 9.0.

\section{Results}

One hundred and forty two patients were eligible for the study. Twelve patients were excluded because they moved away at the start $(n=7)$, had a language problem $(n=3)$, or refused to participate $(n=2)$. Thus 130 patients were included in the study.

Complete data after one year's follow up were obtained from $114(88 \%)$ of the 130 patients. Three patients died (two from malignancy and one from renal failure), four patients refused to participate, and nine had incomplete follow up data-namely, insufficient radiographic data, clinical data, or the questionnaires were incomplete. The baseline disease characteristics of the 16 patients lost to follow up were similar to those of the 114 who completed the trial (data not shown).

Table 1 presents demographic and baseline clinical data on the 130 patients with RA studied. The median disease duration at entry was three months (range 0-24).

The baseline joint damage correlated significantly with age $(p<0.01), E S R$, swollen joint count, and duration of complaints $(\mathrm{p}<0.05)$. Patients were categorised according to the duration of complaints into five centile groups: 0-7 weeks, 8-13 weeks, 14-19 weeks, 20-33 weeks, and 34-104 weeks. By one way analysis of variance it was illustrated that the mean joint damage score at baseline was higher among the patients with a longer duration of complaints $\left(F_{4,123}=2.75 ; p<0.05\right)$. The mean difference in baseline joint damage score between the group with $0-7$ weeks' and more than 34 weeks' duration of complaints was $-7.0 \quad(\mathrm{p}=0.027$, confidence interval (CI) -13.2 to -0.82 ), and 
Table 2 Summaries of logistic regression analysis of baseline variables to predict severely progressive joint damage (Sharp/van der Heijde) at one year

\begin{tabular}{llllll}
\hline Criterion predictor $(n=114)$ & $\begin{array}{l}\text { Coefficient } \\
(\beta)\end{array}$ & $\begin{array}{l}\text { Standard } \\
\text { error }\end{array}$ & $\begin{array}{l}\text { Odds ratio } \\
(\exp \beta)\end{array}$ & $95 \%$ CI & Multiple $R^{2}$ \\
\hline (Constant) & -3.08 & 0.78 & & & $72 \%$ \\
Joint damage at entry & 0.07 & 0.03 & 1.07 & 1.02 to 1.12 & \\
CRP $^{\star}$ high/low & 1.28 & 0.43 & 3.59 & 1.53 to 8.39 & \\
IgM RF ${ }^{\star}$ positivity & 0.95 & 0.43 & 2.58 & 1.11 to 5.97 & \\
Variables not in the equation & Score & $p$ Value & & & \\
Disease duration & 2.01 & 0.16 & & & \\
Age & 0.19 & 0.67 & & & \\
ESR ${ }^{\star}$ high/low & 0.48 & 0.49 & & & \\
DAS & 1.08 & 0.29 & & & \\
Female sex & 2.59 & 0.11 & & & \\
No of tender joints & 0.37 & 0.54 & & & \\
No of swollen joints & 0.02 & 0.89 & & & \\
HAQ & 0.43 & 0.51 & & & \\
\end{tabular}

${ }^{\star} \mathrm{CRP}=\mathrm{C}$ reactive protein $\mathrm{RF}=$ rheumatoid factor; $\mathrm{ESR}=$ erythrocyte sedimentation rate; DAS $=$ disease activity score $\mathrm{HAQ}=$ Health Assessment Questionnaire.

the difference in baseline joint damage between the $8-13$ weeks and the 34-104 weeks group was $-9.65(p=0.002, C I-15.6$ to -3.8$)$ (fig 1$)$.

During the one year follow up, $85 \%$ of the patients were treated with DMARDs: sulfasalazine $(47 \%)$, methotrexate $(22 \%)$, hydroxychloroquine (13\%), and auranofin (2\%). Prednisone was used by nine patients as well.

Table 2 shows the results of the logistic regression analysis of radiographic progression at one year. The median radiographic progression rate was 3 Sharp/van der Heijde score units a year (range -7 to 77 ). Radiographic progression at one year was independently associated with high joint damage, high CRP level, and a positive IgM RF at initial presentation. The duration of complaints and the ESR were significantly correlated $(p<0.05)$ with radiographic progression but had no additional value for the prediction of progression and were therefore not included in the regression model.

\section{Discussion}

In this cohort of patients with very early RA, patients with a delay in referral of more than nine months had a higher joint damage score at entry than patients with a shorter delay. After one year of follow up the duration of complaints was also significantly correlated with the rate of radiographic progression in that year. In the predictive model of radiographic progression within one year the baseline joint damage score, CRP score, and IgM RF positivity proved to have a higher association with radiological progression than the duration of complaints at first visit. Patients with a long duration of complaints had more erosions at diagnosis and also showed more radiographic progression during the first year. In contrast, patients with a low number of erosions at entry had a short period of complaints and had little radiographic progression during the first year.

In this study, the Sharp/van der Heijde method was preferred to the Larsen scoring method. According to Giovagnoni et al, the Sharp/van der Heijde score index can be considered as the best tool for evaluating patients with early RA because of its sensitivity in detecting early disease signs and the possibility of expressing anatomical damage progression quantitatively. ${ }^{32}$ To avoid bias as a result of the fact that the observer may expect progression of damage over time ( that is, overestimation), it was decided to read the radiographs in pairs with unknown time sequence. In the present cohort radiographic damage showed an improvement in $9 \%$ of the patients, which may be due to intraobserver variability, different positioning, or smoothing of the surface.

Our findings about the effects of treatment delay are in accordance with the results of Irvine et al. $^{33}$ They concluded that $73 \%$ of patients who had a one year delay from symptom onset until the first visit to the rheumatologist already showed erosive changes, compared with $34 \%$ of patients seen within one year.

In the present study, patients were categorised into five centile groups according to disease duration. The group with the longest duration of complaints showed the highest score in radiographic joint damage and a higher percentage of patients with RF positivity compared with the shortest delay group $(68 \% v$ $29 \%$ ). However, this does not imply that the IgM RF level is causally related to duration of complaints.

Most studies agree that a positive $\operatorname{IgM} R F$ is an important predictor for joint damage in the first years of disease. ${ }^{3414-17}$ Also for the long term, IgM RF positivity is associated with an unfavourable prognosis. Kaarela et al concluded that $99 \%$ of patients, fulfilling four 1987 American Rheumatism Association criteria for RA, including a positive $\operatorname{Ig} M \mathrm{RF}$, had developed erosive disease after 17 years of disease duration. ${ }^{34}$ In the present study as in that of van der Heijde et $a l^{25}$ the baseline joint damage was a stronger predictor of progression then the IgM RF. Van der Heijde concluded that patients with little radiographic progression could already be identified at one year of follow up. Moreover, it was found that an already damaged joint is more prone to become seriously damaged than an unaffected joint. In contrast with this, Coste et al found, in a two year follow up study, that only disease duration and age were predictive of joint damage progression. ${ }^{35}$

In our study, the duration of complaints correlates with baseline joint damage. This correlation was not found when correlating the baseline HAQ score with patient delay in the same cohort. ${ }^{26}$ Others have also found that joint damage and HAQ scores are not related in the earliest phases of RA. ${ }^{36}$ The link between damage and disability is strongest in late $(>8$ years) RA. This is confirmed by DrossaersBakker et al, who found the correlation between the Sharp/van der Heijde score and the HAQ score to be weak at study start but strong after 12 years. ${ }^{37}$ According to Guillemin et al, physical disability in early RA is mainly determined by disease activity, whereas joint damage becomes more important in a later stage of the disease. ${ }^{38}$

In conclusion, patients should be referred to a rheumatologist as soon as possible in order to initiate treatment with DMARDs rapidly, 
especially in case of RF positivity and a high CRP level.

We thank Janneke de Bruin for the scoring of the $x$ rays.

1 van der Horst-Bruinsma IE, Speyer I, Visser H, Breedveld FC, Hazes JM. Diagnosis and course of early-onset arthritis: results of a special early arthritis clinic compared to tis: results of a special early arthritis clinic compared
routine patient care. Br J Rheumatol 1998;37:1084-8.

2 van Leeuwen MA, van Rijswijk MH, van der Heijde DM, Te van Leeuwen MA, van Rijswijk MH, van der Heijde DM, Te
MG Riel PL, Houtman PM, et al. The acute-phase MG, van Riel PL, Houtman PM, et al. The acute-phase response in relation to radiographic progression in early
rheumatoid arthritis: a prospective study during the first rheumatoid arthritis: a prospective study during the first
three years of the disease. Br J Rheumatol 1993;32(suppl three years $9-13$.
3):

3 Fuchs HA, Kaye J, Callahan LF, Nance-EP J, Pincus T. Evidence of significant radiographic damage in rheumatoid arthritis within the first 2 years of disease. J Rheumatol 1989;16:585-91

4 Kuper HH, van Leeuwen MA, van Riel PL, Prevoo ML, Houtman PM, Lolkema WF, et al. Radiographic damage in large joints in early rheumatoid arthritis: relationship with radiographic damage in hands and feet, disease activity, and physical disability. Br J Rheumatol 1997;36:855-60.

5 van der Heijde DM. Joint erosions and patients with early rheumatoid arthritis. Br J Rheumatol 1995;34(suppl 2):74-8.

6 Salaffi F, Carotti M, Lamanna G, Baldelli S. L'analisi quantitativa della progressione radiologica nell'artrite reumatoide: controversie e prospettive [Quantitative analysis of radiologic progression in rheumatoid arthritis: controversies and perspectives]. Radiol Med (Torino) 1997;93:174-84.

7 Corbett M, Dalton S, Young A, Silman A, Shipley M. Factors predicting death, survival and functional outcome in a prospective study of early rheumatoid disease over fifteen years. Ann Rheum Dis 1993;32:717-23.

8 van Jaarsveld CH, Jacobs JW, van der Veen MJ, Blaauw AA, Kruize AA, Hofman DM, et al. Aggressive treatment in early rheumatoid arthritis: a randomised controlled trial. On behalf of the Rheumatic Research Foundation Utrecht, the Netherlands. Ann Rheum Dis 2000;59:468-77.

9 Boers M, Verhoeven AC, Markusse HM, van de Laar MAFJ, Westhovens R, van Denderen JC, et al. Randomised comparison of combined step-down prednisolone, methotrexate and sulphasalazine with sulphasalazine alone in trexate and sulphasalazine with sulphasalazine alo
early rheumatoid arthritis. Lancet 1997;350:309-18.

10 Stenger AA, van Leeuwen MA, Houtman PM, Bruyn GA, Speerstra F, Barendsen BC, et al. Early effective suppression of inflammation in rheumatoid arthritis reduces radiographic progression. Br J Rheumatol 1998;37:1157-63.

11 Emery P, Marzo H, Proudman S. Management of patients with newly diagnosed rheumatoid arthritis. Rheumatology (Oxford) 1999;38(suppl 2):27-31

12 Abu-Shakra M, Toker R, Flusser D, Flusser G, Friger M, Sukenik $S$, et al. Clinical and radiographic outcomes of rheumatoid arthritis patients not treated with diseasemodifying drugs. Arthritis Rheum 1998;41:1190-5.

13 Feigenbaum SL, Masi AT, Kapoor S. Prognosis in rheumatoid arthritis: a longitudinal study of newly diagnosed younger adult patients. Am J Med 1979;66:377-84.

14 van der Heide A, Remme CA, Hofman DM, Jacobs JW, Bijlsma JW. Prediction of progression of radiologic damage in newly diagnosed rheumatoid arthritis. Arthritis Rheum in newly diagnosed

15 Eberhardt KB, Rydgren LC, Pettersson H, Wollheim FA. Early rheumatoid arthritis-onset, course, and outcome Early rheumatoid arthritis - onset, course, a

16 Matsuda Y, Yamanaka H, Higami K, Kashiwazaki S. Time lag between active joint inflammation and radiological progression in patients with early rheumatoid arthritis. J Rheumatol 1998;25:427-32.

17 van Zeben D, Hazes JM, Zwinderman AH, Vandenbroucke JP, Breedveld FC. Factors predicting outcome of rheumatoid arthritis: results of a followup study [published erratum appears in J Rheumatol 1993;20:2179] [see comments]. J Rheumatol 1993;20:1288-96.

18 Kaarela K. Prognostic factors and diagnostic criteria in early rheumatoid arthritis. Scand J Rheumatol 1985;57(suppl): $1-54$.
19 Young A, Corbett M, Winfield J, Jaqueremada D, Williams P, Papasavvas G, et al. A prognostic index for erosive changes in the hands, feet, and cervical spines in early rheumatoid arthritis. Br J Rheumatol 1988;27:94-101.

20 van der Heijde DMFM, van Riel PLCM, van Leeuwen MA, van 't Hof MA, van Rijswijk MH, van de Putte LBA. Prognostic factors for radiographic damage and physical disability in early rheumatoid arthritis. A prospective followup study of 147 patients. Br J Rheumatol 1992;31: 519-25.

21 van Leeuwen MA, Westra J, van Riel PL, Limburg PC, van Rijswijk MH. IgM, IgA, and IgG rheumatoid factors in early rheumatoid arthritis predictive of radiological progression? [see comments]. Scand J Rheumatol 1995;24: $146-53$.

22 Brennan P, Harrison B, Barrett E, Chakravarty K, Scott D, Silman A, et al. A simple algorithm to predict the development of radiological erosions in patients with early rheumatoid arthritis: prospective cohort study. BMJ 1996; 313:471-6.

23 van Leeuwen MA, van Rijswijk MH, Sluiter WJ, van Riel $\mathrm{PL}$, Kuper $\mathrm{IH}$, van de Putte LB, et al. Individual relationship between progression of radiological damage and the acute phase response in early rheumatoid arthritis. Towards development of a decision support system. J Rheumatol 1997;24:20-7.

24 Plant MJ, Jones PW, Ollier WER, Dawes PT. Early rheumatoid arthritis: $50 \%$ of longterm radiological progression can be predicted in the first year [abstract]. Br J Rheumatol 1996;35(suppl):206.

25 van der Heijde DM, van Leeuwen MA, van Riel PLCM, Koster AM, van 't Hof MA, van Rijswijk MH, et al. Biannual radiographic assessments of hands and feet in a three-year prospective followup of patients with early rheumatoid arthritis. Arthritis Rheum 1992;35:26-32.

26 Jansen LMA, van Schaardenburg D, van der Horst Bruinsma IE, Bezemer PD, Dijkmans BA. Predictors of functional status in patients with early arthritis. Ann Rheum Dis 2000;59:223-6.

27 Arnett FC, Edworthy SM, Bloch DA, McShane DJ, Fries JF, Cooper NS, et al. The American Rheumatism Association 1987 revised criteria for the classification of rheumatoid arthritis. Arthritis Rheum 1988;31:315-324.

28 Prevoo ML, van 't Hof M, Kuper HH, van Leeuwen MA, van de Putte LB, van Riel PL. Modified disease activity scores that include twenty-eight joint counts: development and validation. Arthritis Rheum 1995;38:44-8.

29 Bijlsma JW, Oude Heuvel CHB, Zaalberg A. Development and validation of the Dutch questionnaire capacities of daily life (VDF) for patients with rheumatoid arthritis. J Rehabil Sci 1990;3:71-4.

30 Sharp JT. Radiographic evaluation of the course of articular disease. Clin Rheum Dis 1983;9:541-57.

31 Altman DG. Practical statistics for medical research. London: Chapman and Hall, 1991.

32 Giovagnoni A, Valeri G, Burroni E, Amici F. Rheumatoid arthritis: follow-up and response to treatment. Genet Epidemiol 1999;27(suppl 1):25-30.

33 Irvine S, Munro R, Porter D. Early referral, diagnosis, and treatment of rheumatoid arthritis: evidence for changing medical practice. Ann Rheum Dis 1999;58:510-13.

34 Kaarela K, Luukkainen R, Koskimies S. How often is seropositive rheumatoid arthritis an erosive disease? A 17-year followup study. J Rheumatol 1993;20:1670-3.

35 Coste J, Spira A, Clerc D, Paolaggi JB. Prediction of articular destruction in rheumatoid arthritis: disease activity markers revisited. J Rheumatol 1997;24:28-34.

36 Scott DL, Pugner K, Kaarela K, Doyle DV, Woolf A, Holmes J, et al. The links between joint damage and disability in rheumatoid arthritis. Rheumatology (Oxford) 2000;39:122-32.

37 Drossaers-Bakker KW, de Buck M, van Zeben D, Zwinderman AH, Breedveld FC, Hazes JMW. Long-term course and outcome of functional capacity in rheumatoid arthritis. Arthritis Rheum 1999;42,:1854-60.

38 Guillemin F, Briancon S, Pourel J. Functional disability in theumatoid arthritis: two different models in early and established disease. J Rheumatol 1992;19:366-9. 